\title{
Comparative Analysis of the Different Brassica Oleracea Varieties Grown on Jos, Plateau Using Albino Rats.
}

\author{
Mohammed, $\mathrm{A}^{1}$ and Luka, C. $\mathrm{D}^{2}$ \\ ${ }^{1}$ Department of Biochemistry, Faculty of Pure \& Applied Sciences, Federal University Wukari.Nigeria. \\ ${ }^{2}$ Department of Biochemistry, Faculty of Medical Sciences, University of Jos. Nigeria.
}

\begin{abstract}
This study was carried out to determine and compare the phytochemical, anti-nutrients, proximate composition and the effects of Brassica oleracea varieties on hepatic and erythropoietic parameters such as liver enzymes and packed cell volume (PCV) respectively. Fresh samples of the different varieties of Brassica oleracea namely: Brassica oleracearepa(Chinese cabbage), Brassica oleracearupetris(red cabbage) and Brassica oleraceapeviridis(green cabbage) were collected from Kasa in Plateau state, Nigeria, and were identified. After the authentication of these samples, the effect of gastric inturbation (oral administration) of the aqueous extracts on Male White Albino rats was observed for 14days. Each of the three (3) varieties were analysed for proximate composition, phytochemicals and anti-nutrients. It was observed that Brassica olereceais an important source of nutrients, particularly minerals. However, the high content of anti-nutritional factors such as cyanides, tannins, oxalates and phytic acids make these minerals bio-unavailable due to the process of chelation. It was also observed that the 3 varieties could have possible effects in the reduction of packed cell volume (PCV)/ Haemoglobin ( $\mathrm{Hb})$ levels and in the elevation of liver enzymes activity (Alkaline phosphate, ALT and AST). One could therefore conclude that there is a change in $\mathrm{PCV} / \mathrm{Hb}$ levels and liver enzymes activity of extract-fed subjects from Brassica oleraceavarieties to the control subjects from normal diet.
\end{abstract}

Keywords:Antitnutritionalfactors,Brassica oleracea, Liver enzymes,oral inturbation,Phytochemical, Proximate composition.

\section{Introduction}

Vegetables have a wide area of application and nutritional values. Each however, requires certain minimum quality of nutrition because the principle of nutrition for all animals is anchored on the whole content of balanced diet [1]. Brassica oleracea (cabbage) is a plant of Brassicacea (or Cruciferae). It is an herbaceous, biennial and dicotyledonous flowering plant with leaves forming a characteristic compact cluster. The most commonly grown varieties of Brassica oleracea on Jos, Plateau are the Green, Red and Chinese cabbage respectively in their order of demand. The favourable climatic condition of Jos, Plateau contributes immensely to the commercial and subsistence production of these three (3) varieties. Brassica oleraceahas both nutritional \& medicinal benefits. The nutritional benefits among others include it's been a rich source of nutrients such as Minerals (Ca, K, P, Fe, Mg \& Zn), Vitamins such as B-complex vitamins and ascorbic acid, Carbohydrates, fats, proteins \& water [2].The medicinal health benefits are a function of the nutritional properties some of which include lower risk of heart attack, birth defects, lung cancer, obesity and intestinal uncomfortability [3].

However, Brassica oleracea varieties also contains corresponding high amount of anti-nutrients such as phytic acid, cyanides, oxalate, tannins and glycosides, which makes some of the mineral nutrients biounavailable due to process of chelation.Prolonged bio-unavailability of essential nutrients can result to metabolic derangement and consequently leads to dietary deficiency diseases [4].The human liver is one of the largest delicate and complex organs in the body with enormous functions among which include osmoregulation, detoxification and metabolism. Some of the normal roles of the liver may be altered if tissue injury occurs at specific sites [5]. This is the case with prolonged use of the immuno-suppressive plant extract of Brassica oleraceafor nutritional and medicinal purposes. The study of the different Brassica oleraceavarieties grown in Jos, Plateau seeks to determine \& compare whether there are differences in the nutrient contents, phytochemicals, anti-nutrients of the plants and their effects on both hepatic and erythropoietic parameters [6]. This is also expected to influence populations that dwell strictly on the plant as food.

\subsection{Collection of plants materials}

\section{Materials And Methods}

As far as possible analytical reagents, biochemical and standard laboratory equipments were used throughout the experiments. Fresh samples, each of the 3 commonly grown varieties of Brassica oleracea (Green, Red and Chinese cabbage) were collected from Kasa, Barkin-Ladi L.G.A of Plateau stateand were authenticated at the Botany Department of University of Jos. 


\subsection{Extraction and Administration of the Extract}

They were sliced and dried separately. A portion of the dried powdered sample was used for both proximate composition, phytochemicals and ant-inutrients composition analysis at N.V.R.I Vom. 40g each of the plant was dissolved in $500 \mathrm{mls}$ of water for aqueous extraction and $0.2 \mathrm{mls}$ of the extract were orally intubated into 3 groups each of 9 male white albino Wistar rats.

\subsection{Collection of Experimental Animals}

The rats were collected from the Animal house, Anatomy department; University of Jos, housed in Aluminium cages. The rats were also fed Guinea feed growers mash in addition to the extract with the exception of the control group (Rats fed on only diet). The weights of the animals were monitored on the alternate days throughout the experimental periods and were found to be between the ranges of 140-150grams.

\subsection{Experimental grouping}

The rats were divided into four groups of nine animals each and are allowed to acclimatize for three days before the commencement of the study. The experimental groupings are A,B,C and D.

Group A: Rats fed with Green cabbage extract

Group B: Rats fed with Red cabbage extract

Group C: Rats fed with Chinese extract

Group D: Rats fed with Normal diet

\subsection{Collection of blood sample}

At the end of 14days, blood was collected into heparinized haemotocrit tubes from the tails of each group on alternate times and was analyzed for $\mathrm{PCV} / \mathrm{Hb}$ levels. Also, sacrificial blood was collected into plain tubes for liver enzymes analysis.

\subsection{Statistical analysis}

Means were compared using the students T-test. The levels of significance was determined by placing $\mathrm{P}<0.05$ in two-tailed frequency distribution table.

\section{Results}

TABLE 1:Resultsof Proximate Composition of the three (3) varieties of Brassica oleracea (in $\mathrm{mg} / 100 \mathrm{~g}$ of dry samples)

\begin{tabular}{|l|l|l|l|}
\hline $\begin{array}{l}\text { Proximate } \\
\text { composition }\end{array}$ & Green cabbage & Red cabbage & Chinese cabbage \\
\hline Moisture $(\%)$ & $14.80 \pm 0.02$ & $8.35 \pm 0.61$ & $12.28 \pm 0.62$ \\
\hline $\begin{array}{l}\text { Crude protein } \\
(\mathrm{g})\end{array}$ & $30.09 \pm 1.09$ & $26.67 \pm 0.38$ & $31.98 \pm 1.04$ \\
\hline Crude fibre $(\mathrm{g})$ & $33.31 \pm 1.19$ & $44.87 \pm 0.05$ & $17.00 \pm 0.09$ \\
\hline Crude fat $(\mathrm{g})$ & $0.52 \pm 0.04$ & $0.85 \pm 0.06$ & $1.23 \pm 0.43$ \\
\hline Ash $(\mathrm{g})$ & $7.96 \pm 0.08$ & $9.77 \pm 0.77$ & $10.18 \pm 0.71$ \\
\hline $\mathrm{NFE}(\mathrm{g})$ & $35.12 \pm 0.27$ & $17.84 \pm 0.09$ & $39.61 \pm 0.61$ \\
\hline $\mathrm{Ca}(\mathrm{g})$ & $1.76 \pm 0.04$ & $0.96 \pm 0.09$ & $0.68 \pm 0.08$ \\
\hline $\mathrm{P}(\mathrm{g})$ & $0.86 \pm 0.09$ & $1.89 \pm 0.19$ & $0.64 \pm 0.04$ \\
\hline
\end{tabular}

TABLE 2: Results of Anti-nutrients factors of the 3 varieties of Brassica oleraceaplant (in mg/100g of dry samples)

\begin{tabular}{|l|l|l|l|}
\hline $\begin{array}{l}\text { Anti-nutrients } \\
(\mathrm{mg} / 100 \mathrm{~g})\end{array}$ & Green cabbage & Red cabbage & Chinese cabbage \\
\hline Tannins & $1.50 \pm 0.54$ & $1.57 \pm 0.39$ & $1.57 \pm 0.36$ \\
\hline Oxalate & $225.00 \pm 6.60$ & $265.06 \pm 13.70$ & $265.00 \pm 13.70$ \\
\hline Phytic acid & $27.83 \pm 0.40$ & $30.36 \pm 0.90$ & $27.83 \pm 0.40$ \\
\hline Cyanide & $82.50 \pm 2.60$ & $82.50 \pm 2.80$ & $75.63 \pm 1.60$ \\
\hline
\end{tabular}


TABLE 3: Percentage (\%) change in $\mathrm{PCV} / \mathrm{Hb}$ levels for rats fed with normal diet (control) and extract-fed rats (test)

\begin{tabular}{|l|l|l|}
\hline Groups & \% change in PCV & \% change in Hb levels \\
\hline Group A & $41.00 \pm 2.70$ & $14.80 \pm 0.90$ \\
\hline Group B & $32.00 \pm 2.00 \mathrm{a}$ & $11.60 \pm 0.80 \mathrm{a}$ \\
\hline Group C & $22.00 \pm 3.60 \mathrm{ab}$ & $7.90 \pm 1.30 \mathrm{ab}$ \\
\hline Group D & $42.00 \pm 5.30 \mathrm{c}$ & $15.10 \pm 1.90 \mathrm{c}$ \\
\hline
\end{tabular}

$\mathrm{a}=$ statistically significantly different when compared to $\mathrm{A}$ at $\mathrm{p}<0.05$

$\mathrm{b}=$ statistically significantly different when compared to $\mathrm{B}$ at $\mathrm{P}<0.05$

$\mathrm{c}=$ statistically significant different when compared to $\mathrm{C}$ at $\mathrm{P}<0.05$

TABLE 4: Results of some plasma enzyme activity and other biochemical indices for rats fed with normal diet and rats fed with diet extracts of the 3 varieties of Brassica oleraceaplant.

\begin{tabular}{|l|l|l|l|l|l|l|}
\hline Groups & $\begin{array}{l}\text { GOT/AST } \\
(\mathrm{iu} / \mathrm{L})\end{array}$ & $\begin{array}{l}\text { GPT/ALT } \\
(\mathrm{iu} / \mathrm{L})\end{array}$ & $\begin{array}{l}\text { Alkaline phosphate } \\
(\mathrm{iu} / \mathrm{L})\end{array}$ & $\begin{array}{l}\text { Total protein } \\
(\mathrm{g} / \mathrm{L})\end{array}$ & $\begin{array}{l}\text { Albumin } \\
(\mathrm{g} / \mathrm{L})\end{array}$ \\
\hline Group A & $94.00 \pm 3.60$ & $30.00 \pm 3.90$ & $126.00 \pm 2.00$ & $82.00 \pm 2.00$ & $25.00 \pm 2.30$ \\
\hline Group B & $97.00 \pm 4.60$ & $37.00 \pm 7.20$ & $170.00 \pm 0.70 \mathrm{a}$ & $51.00 \pm 1.80 \mathrm{a}$ & $27.00 \pm 2.70$ \\
\hline Group C & $51.00 \pm 2.00 \mathrm{ab}$ & $25.00 \pm 2.00$ & $144.00 \pm 0.50 \mathrm{ab}$ & $80.00 \pm 3.70$ & 30.00 \\
& & & & & $4.00 \mathrm{~b}$ & \pm \\
\hline Group D & $\begin{array}{l}40.00 \\
2.70 \mathrm{abc}\end{array}$ & $25.00 \pm 1.40 \mathrm{~b}$ & $144.00 \pm 0.70 \mathrm{ab}$ & $87.00 \pm 3.00 \mathrm{~b}$ & $\begin{array}{l}27.00 \\
4.60 \mathrm{c}\end{array}$ \\
\hline
\end{tabular}

$\mathrm{a}=$ statistically significantly different when compared to $\mathrm{A}$ at $\mathrm{p}<0.05$

$\mathrm{b}=$ statistically significantly different when compared to $\mathrm{B}$ at $\mathrm{P}<0.05$

$\mathrm{c}=$ statistically significant different when compared to $\mathrm{C}$ at $\mathrm{P}<0.05$

\section{Discussion}

The results of the phytochemical studies showed that Alkaloids, Saponins, Cardiac glycosides, Resins and terpenes/steroids are present in the 3 Brassica oleracea varieties. However, Tannins, Balsam and Phenol are not present in the 3 varieties and Flavonoids is absent in only the Red cabbage variety but its present in the Green and Chinese cabbage varieties which is in line with findings of Sousa [7].From Table 1, results showed that Green variety contains high amount of moisture content $(14.80 \pm 0.62)$ and calcium $(1.76 \pm 0.04)$ than the Red and Chinese varieties. The Red variety has high amount of crude fibre $(44.87 \pm 1.05)$ and phosphorus (1.89 $\pm 0.19)$ than the Green and Chinese varieties. Crude protein $(31.98 \pm 1.04)$, crude fat $(1.23 \pm 0.43)$, nitrogen free extract NFE $(39.61 \pm 0.66)$ and Ash $(10.18 \pm 0.71)$ were found to be higher in the Chinese variety than the red and Green varieties. The results from the Table 2 showed that Red and Chinese varieties have equal amount of Tannins $(1.57 \pm 0.39)$ and Oxalate $(265.00 \pm 13.70)$ and values are higher than Green cabbage $(1.50 \pm 0.54$ and $255.00 \pm 6.00)$ respectively. Cyanide is present in the equal amount in Green and Red cabbage varieties $(82.50 \pm$ $2.60)$ per each. Both Green and Chinese cabbage varieties contain equal amount of phytic acid (27.83 \pm 0.40$)$. However, red cabbage contains high amount of phytic acid (30.36 \pm 0.90$)$ than Green and Chinese varieties.

Table 3 shows that rats fed with Chinese, green and red cabbage extracts (Groups A,B, and C) have reduced PCV and haemoglobin levels at the end of the 14days of experimental period compared to the normal/control group D, results from the table 4 showed that there were significant increase in the serum levels of the plasma enzymes activities and other biochemical indices for the case samples when compared to the control group, revealing health problems of various degree which may be occasioned by liver and pancreatic damage [8]. The disease conditions associated with the elevated determined biochemical parameters are as follows; increased levels of alkaline phosphatase may indicate cholestasis, liver tumors and obstructive biliary disease. Increased levels of transaminases may indicate hepatocellular destruction, myocardial infarction, liver cirrhosis, severe pancreatitis, shock liver, toxic hepatitis, mononucleosis, and post-hepatic biliary obstructive disease haemolysis[9].

\section{Conclusion}

Since Brassica oleracea varieties contains high amount of nutrients and anti-nutrients, it is important to encourage further studies on the mineral profile composition and the method of reducing the ratio of the antinutrients to the nutrients component to provide beneficial health effects to the body without decreasing nutrients bio-availability. 


\section{References}

[1] R. Hall,Brassicaoleraceae(AcephalaGroup).USDA Database for Standard Reference,Release 12 (March, 1998). about..com. Nutritionguide. http://www.nutrition.about.com. Accessed10/4/2009.

[2] E.A.S,Rosa, Glucosinolates from flower buds of Portuguese Brassica crops, Phytochemistry 1997,44: 1415-1419.

[3] A.U, Osagie, Anti-nutritional factors in nutritional quality of plant food,1998,Pg 221-244

[4] E.W Chipman and E. Thorpe . Effects of maturity and frost on the leaf colour of storage cabbage.Canadian journal of plant science. 1978, 59: 429-435

[5] Berg J,Tymoczko, L,Stryer, Biochemistry, 5th Edition, San fransisco, W.H. Freeman,2002, 603

[6] E.P.A, Summary review of health effects associated with Hydrogen cyanide, health issue assessment; Environmental criteria and assessment office, Office of Health and Environmental Research and Development, US Environmental Protection Agency, triangle park, North Carolina, 1990

[7] C. Sousa1, P. Valentão, M. david, Phytochemical and Antioxidant Characterization of Brassica oleracea Var. CostataExtracts $18,2009,311-339$.

[8] E.U Onyeka and I.O. Nwambekwe,Phytochemical profile of some green leafyvegetables in South East Nigeria., Nig. Food J. 2007, 25:67-76.

[9] P.K. Emebu and J.U. Anyika.Vitamin and Antinutrient Composition of Kale (Brassica oleracea) Grown in Delta State, Nigeria.Pakistan Journal of Nutrition 10 (1)2011, 76-79. 